\title{
Cobertura de solo e produção de porongo sob diferentes configurações de cultivo
}

\author{
Soil cover and yield of bottlegourd under different crop configurations
}

\author{
Daniela Batista dos Santos ${ }^{\mathrm{I}}$ Claudia Petry' ${ }^{\mathrm{II}}$ Edson Campanhola Bortoluzzi ${ }^{\mathrm{II}^{*}}$
}

RESUMO

Em pequenas propriedades rurais, o cultivo tradicional de porongo é ainda frequente em solos declivosos e rasos, resultando na degradação do solo e na baixa produtividade. O trabalho teve por objetivo estudar diferentes densidades e épocas de cultivo para a espécie Lagenaria siceraria (Mol.) Standl. (porongo), a fim de proporcionar rápida cobertura vegetal do solo, maior produtividade e melhor qualidade de frutos comercializáveis. Três experimentos sob delineamento inteiramente casualizado com quatro repetições foram instalados em 15/09/07, 06/10/07 e 27/10/07, no norte do Rio Grande do Sul, em um Latossolo Vermelho preparado sob sistema plantio convencional (SPC). A semeadura foi em covas nas densidades de 1600 e 400 covas ha-1, representados por espaçamentos de 2,5x2,5m e 5x5m (tradicional da região), respectivamente. Foram avaliados o ciclo da cultura, o número e o comprimento das ramas principais aos 60 dias após a emergência (DAE), a cobertura vegetal do solo aos $0,30,60$, 90 e 150DAE, a qualidade e a produtividade dos frutos. Após análise conjunta dos dados dos experimentos, observou-se que as plantas semeadas em 27/10/07, em ambas as densidades, apresentaram ciclo (150 dias), tamanho de frutos $e$ produtividade menores; porém, sob a densidade de 1600 covas ha $^{-1}$ (espaçamento de 2,5x2,5m), houve, aos 30DAE, a maior cobertura vegetal do solo $(93,7 \%)$ em relação às demais épocas. Sob essa densidade, o cultivo em qualquer época estudada apresentou cobertura do solo mais rápida $e$ produtividades de frutos comerciais (cuias) maiores que o cultivo sob densidade tradicional.

Palavras-chave: cobertura do solo, pequena propriedade, sistema plantio convencional, Lagenaria siceraria (Mol.) Standl.

\section{ABSTRACT}

In small farms, the traditional cropping system on slope and shallow soils is often common, resulting in soil and water degradation and low productivity. The study aimed to investigate different configuration of cultivations (density and times of sown) of Lagenaria siceraria (Mol.) Standl. species (bottlegourd), intending to promote faster soil mulching, to increase productivity and to obtain better quality of marketable fruits. Three experiments in completely randomized design with four replicates were installed at 15/09/07, 06/10/07 and 27/10/ 07 in the northern Rio Grande do Sul in a Red Latosol under conventional tillage system (SPC). The sown was made on holes with $2.5 \times 2.5$ and $5.0 \times 5.0 \mathrm{~m}$ spacing, considered traditional, and with 1,600 and 400 holes ha $\mathrm{s}^{-1}$ density, respectively. It was evaluated the crop cycle, the number and length of main stems 60 days after emergence (DAE), the soil mulching at 0, 30, 60, 90 and, 150DAE and, quality and fruit productivity. A joint analysis of data from experiments showed that the plants sown on 27/10/07, in both spacing, showed lower cycle (150 days), fruit size and productivity, but under 1,600 holes $\mathrm{ha}^{-1}$ (2.5x2.5m of sown spacing), there was at 30DAE a faster soil mulching (93.7\%) than in other sown times. In the same holes density, at any time of sown, it was shown that $2.5 \times 2.5 \mathrm{~m}$ spacing, reaches the faster soil mulching and higher yield of fruits than those under traditional sown density.

Key words: soil coverage, small farmers, conventional tillage, Lagenaria siceraria (Mol.) Standl.

\section{INTRODUÇÃO}

As espécies da família Cucurbitaceae, apesar de muitas não serem de origem americana (BISOGNIN, 2002), assumem importante papel na

IFundação Universidade de Passo Fundo (FUPF), Passo Fundo, RS, Brasil.

IFFaculdade de Agronomia e Medicina Veterinária, FUPF, 99001-970, Passo Fundo, RS, Brasil. E-mail: edsonb@upf.br.*Autor para correspondência. 
agricultura brasileira. No Rio Grande do Sul, a espécie Lagenaria siceraria (Mol.) Standl. (porongo) merece destaque, pois do seu cultivo advém o fruto do porongo, matéria-prima para a confecção de cuias utilizadas como recipiente para o chimarrão, bebida típica do Sul da América do Sul (BISOGNIN et al., 2008).

O cultivo dessas espécies é típico de minifúndios (BISOGNIN et al., 1997), os quais, em razão das práticas tradicionais de condução da cultura, como arações e gradagem, oferecem problemas de conservação do solo (ELTZ et al., 2005). Agronomicamente existem carências de informações acerca de práticas adequadas de cultivo e de manejo das espécies que compõem a família das cucurbitáceas que visem a melhorar a produtividade e, ao mesmo tempo, diminuir os riscos de erosão (ELTZ et al., 2005; BISOGNIN et al., 1992; BISOGNIN et al., 1999).

O cultivo do porongo dá-se pelo sistema convencional, com uso de baixas densidades, a fim de permitir o tráfego de máquinas entre as linhas de cultivo, resultando em baixas produtividades (RESENDE \& COSTA, 2003). Além disso, a semeadura realizada nos meses mais chuvosos e o desenvolvimento inicial lento (BISOGNIN et al., 2004) potencializam os problemas de erosão do solo. ELTZ et al. (2005) verificaram que a cobertura de solo na cultura da melancia, no seu primeiro terço do ciclo de desenvolvimento, é baixa sob sistema de plantio convencional. Além de uma boa produtividade, exige-se boa qualidade dos frutos, a qual, por meio de parâmetros como tamanho, formato, densidade do casco do fruto, espessura, dentre outros, define o valor comercial do produto (BISOGNIN et al., 1992; BISOGNIN \& STORCK, 2000). Busca-se, então, com este trabalho, estudar diferentes configurações de cultivo do porongo, testando-se épocas de semeadura e densidades de plantio a fim de aumentar a cobertura vegetal do solo proporcionada pela espécie nos seus estádios iniciais de desenvolvimento, aliada à maior produtividade e à maior qualidade de frutos.

\section{MATERIAL E MÉTODOS}

O trabalho foi conduzido no período de junho de 2007 a maio de 2008, no Município de Rondinha Rio Grande do Sul (RS), num Latossolo Vermelho, a $575 \mathrm{~m}$ de altitude, sob as coordenadas geográficas $27^{\circ} 52^{\prime} 09^{\prime}$ 'Sul e 5255’09” Oeste. A precipitação pluviométrica e a temperatura do ar da região estão na figura 1 .

Na área, manejada com culturas anuais, três experimentos foram instalados nas seguintes épocas de semeadura: 1) 15/09/07; 2) 06/10/07 e 3) 27/10/07, em delineamento experimental inteiramente casualizado, com quatro repetições. Para cada época de semeadura, foram previstas duas densidades de plantio: 1600 covas ha $^{-1}$ (espaçamentos entre covas de 2,5mx2,5m) e 400 covas ha $^{-1}$ (espaçamento entre covas de $5 \mathrm{mx} 5 \mathrm{~m}$ ). Cada parcela foi composta por quatro covas, preparadas com auxílio de enxada, sendo as duas centrais objeto de medições e as outras duas covas utilizadas como bordadura.

Na primavera, antes da instalação dos experimentos, a área sob resteva de milho safrinha foi arada e gradada duas vezes. O solo antes do plantio apresentou as seguintes características: $56 \%$ de argila; matéria orgânica $=3,1 \%$; $\mathrm{pH}$ em água $=6,0 ; \mathrm{P}=3 \mathrm{mg} \mathrm{dm}^{-3}$; $\mathrm{K}=163 \mathrm{mg} \mathrm{dm}^{-3} ; \mathrm{Ca}=7,7 \mathrm{cmol} \mathrm{dm}^{-3}, \mathrm{Mg} 3,3 \mathrm{cmol} \mathrm{dm}^{-3} \mathrm{e}$ $\mathrm{Al}=0,0 \mathrm{cmol}_{\mathrm{c}} \mathrm{dm}^{-3}$, e em mg dm${ }^{-3}$ para $\mathrm{S}=8,0, \mathrm{Zi}=7,6 \mathrm{e}$ $\mathrm{Bo}=0,2$.

A adubação foi de 72 g cova $^{-1}$ de $\mathrm{P}_{2} \mathrm{O}_{5}$ e $36 \mathrm{~g}$ cova $^{-1}$ de $\mathrm{K}_{2} \mathrm{O}$, utilizando-se a fórmula comercial NPK de 0-24-12 oito dias antes da semeadura. A semeadura foi realizada manualmente utilizando-se cinco sementes colocadas na cova a $1,5 \mathrm{~cm}$ de profundidade. Trinta dias após a emergência (DAE) das plântulas, foi feito um desbaste deixando-se apenas três por cova. A adubação nitrogenada de cobertura foi de $4,5 \mathrm{~g} \mathrm{cova}^{-1}$ de $\mathrm{N}$, na forma de ureia, em duas etapas, aos 30 e aos 60DAE. Foi utilizada uma população de polinização aberta de porongo, e a condução da cultura seguiu as utilizadas por produtores na região.

Foram avaliados o ciclo das plantas (data de quando as plântulas emergiram, data da floração plena e data de quando os frutos estavam maduros para serem colhidos) em cada época de semeadura, o número e o comprimento das ramas principais, com auxílio de diastímetro aos 60 dias após a emergência. A cobertura vegetal proporcionada pela cultura foi determinada aos zero, 30, 60, 90 e 150DAE da cultura, em todos os cultivos, segundo o método fotográfico descrito em BORTOLUZZI \& ELTZ (2000), em que fotos digitais representando $3 \mathrm{~m}^{2}$ da parcela foram avaliadas segundo a proporção entre solo coberto pela vegetação e nu.

A colheita dos frutos foi realizada manualmente. Para as épocas de semeadura em 15/09/ 07 e 06/10/07, utilizou-se o número total de frutos de cada tratamento, ou seja, em uma área de $375 \mathrm{~m}^{2}$ para a maior densidade e $187,5 \mathrm{~m}^{2}$ para a menor densidade. $\mathrm{Na}$ terceira época, em 27/10/07, a área útil de cada repetição foi de $30 \mathrm{~m}^{2}$ para a maior densidade e $60 \mathrm{~m}^{2}$ para a menor densidade.

Para as avaliações referentes aos frutos (diâmetros da base e da cuia, comprimento e espessura de casco e massa das sementes), após a colheita, foram coletadas amostras representativas das parcelas, nas 


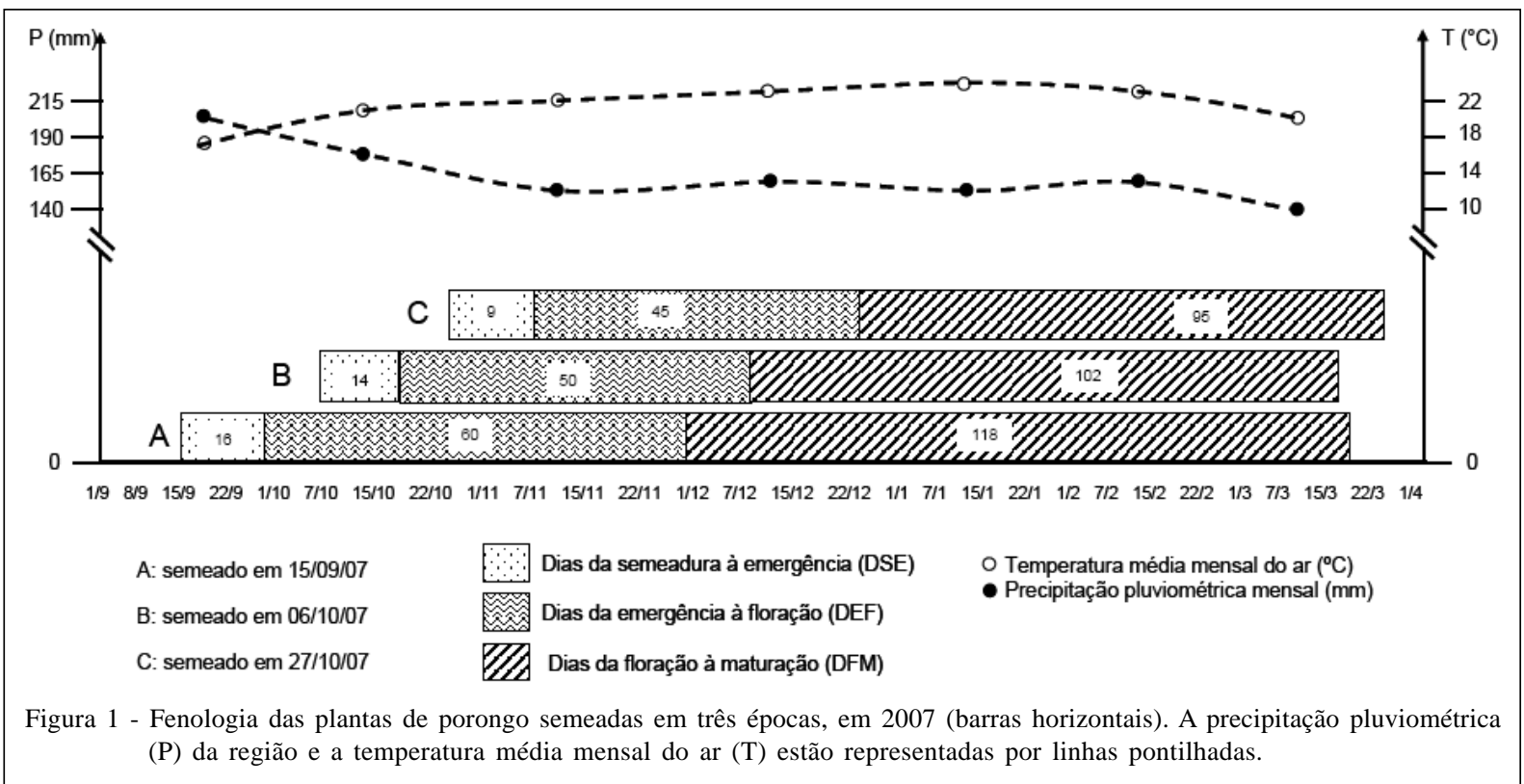

quatro repetições, e 10 frutos constituíam uma repetição. Considerou-se a base dos frutos como sendo o maior diâmetro do porongo, sobre o qual pode-se apoiar o fruto no solo na posição vertical. O comprimento do fruto compreende a distância entre a extremidade apoiada no solo e a extremidade presa ao pedúnculo. Após cortar e medir na região central do fruto, a extremidade oposta à base foi considerada como cuia. Amostras do casco das cuias foram coletadas, e a espessura foi quantificada com um paquímetro. Além disso, a base dos frutos foi mantida em local seco, onde as sementes foram retiradas para posterior avaliação da massa de sementes por fruto, e esse parâmetro foi correlacionado com o tamanho do fruto.

Os dados de cobertura do solo foram submetidos à análise de variância de cada experimento e à análise de regressão entre as épocas. As variáveis relativas à qualidade dos frutos e ao número e comprimento de ramas principais foram submetidas à análise de variância em delineamento DCC. Também foi realizada a análise conjunta dos dados dos três experimentos, e as médias foram comparadas pelo teste de Tukey, em nível de 5\% de significância. Os dados referentes à produtividade de frutos entre os espaçamentos de plantio para a época 27/10/07 foram submetidos ao teste T. Aplicou-se correlação de Pearson entre os dados.

\section{RESULTADOS E DISCUSSÃO}

As plântulas de porongo emergiram entre nove e 16 dias após a semeadura (DSE) (Figura 1).
Houve menor tempo de emergência na semeadura mais tardia, no mês de outubro (27/10/07), em razão do aumento gradual da temperatura média mensal do ar para a época. A mesma tendência foi observada para o período em dias entre a emergência e a floração (DEF) e o período em dias da floração a maturação (DFM). Em todas as épocas de semeadura testadas, a temperatura do ar (Figura 1) manteve-se acima de $16^{\circ} \mathrm{C}$, considerada, segundo RESENDE et al. (2006), temperatura mínima à germinação para a família das cucurbitáceas. A temperatura do ar durante a época de semeadura mais tardia em $27 / 10$ manteve-se ao redor de $20^{\circ} \mathrm{C}$, o que antecipou em sete dias a emergência em relação à primeira e à segunda época de semeadura.

O período em dias da emergência à floração e à maturação dos frutos (DEF e DFM) se apresentou mais longo para as plantas semeadas na primeira época, em 15/09, que para as demais épocas. Isso se deve à prolongação dos estádios fenológicos decorrentes da temperatura abaixo da faixa considerada ótima segundo RESENDE et al. (2006) para o ciclo vegetativo da cultura, que é entre $23^{\circ} \mathrm{C}$ e $28^{\circ} \mathrm{C}$. Nas semeaduras mais tardias, ocorreu diminuição dos períodos DEF e DFM, justificado também pela temperatura, nesse caso, por temperaturas mais altas (Figura 1). Vale notar que a senescência natural das plantas e a maturação dos frutos tenderam a ocorrer no mês de fevereiro do ano seguinte para aquelas semeadas em 15/09 e março para as semeadas tardiamente. A fenologia da cultura responde diferentemente com a época de semeadura, em decorrência da variação da temperatura (BLEASDALE, 1977). 
Quanto à densidade de semeadura, esse parâmetro não apresentou influência sobre o número e o comprimento das ramas principais de porongo, avaliados aos 60DAE (Tabela 1). Já a semeadura realizada em 27/10, considerada tardia para a região, apresentou maior comprimento das ramas principais (Tabela 1). Isso está em acordo com a ocorrência de temperaturas mais elevadas verificadas para essa época.

Em virtude do hábito prostrado da espécie, o crescimento das ramas e o ciclo das plantas podem influir na dinâmica da cobertura do solo. Houve interação entre as épocas de semeadura, densidade de plantio e datas de avaliações (Tabela 2). Na primeira avaliação, a cobertura do solo foi de zero em todos os tratamentos. Aos 30DAE, o espaçamento mais denso de 2,5x2,5m proporcionou maior cobertura do solo que o de 5,0x5,0m. Observa-se também uma maior cobertura do solo em relação às demais quando a semeadura foi realizada tardiamente para a região, em 27/10. Assim, aos 30DAE a cobertura do solo chegou a $93,7 \%$ na semeadura realizada em 27/10, na densidade de 1600 covas ha $^{-1}$ (espaçamento 2,5x2,5m), enquanto que, para as outras épocas de semeadura, esse índice somente foi alcançado aos 60DAE. Isso deve estar relacionado ao fato de que as plantas apresentarem crescimento diferenciado das ramas principais (Tabela 1 ).

Aos 60DAE, apenas a primeira época de plantio (15/09) apresentou diferenças na cobertura de solo entre os espaçamentos avaliados. Para as avaliações aos 90 e 150DAE, não houve diferença entre as épocas de plantio e espaçamentos (Tabela 2). Isso se deve provavelmente ao fato dessas plantas já se

Tabela 1 - Número e comprimento das ramas principais de porongo aos 60 dias após a emergência em função da densidade e das épocas de semeadura.

\begin{tabular}{|c|c|c|}
\hline & $\begin{array}{l}\text { Ramas principais } \\
\text { (unidade) }\end{array}$ & $\begin{array}{l}\text { Comprimento das } \\
\text { ramas principais }(\mathrm{m})\end{array}$ \\
\hline \multicolumn{3}{|c|}{ Densidade de semeadura (covas ha ${ }^{-1}$ ) } \\
\hline 400 & $9,0^{\mathrm{ns}}$ & $20,7^{\text {ns }}$ \\
\hline 1600 & 7,8 & 17,7 \\
\hline \multicolumn{3}{|c|}{ Época de semeadura } \\
\hline $15 / 09 / 07$ & $8,50^{\text {ns }}$ & $14,15 \mathrm{~b}$ \\
\hline 06/10/07 & 7,37 & $18,56 \mathrm{~b}$ \\
\hline $27 / 10 / 07$ & 9,37 & $24,96 a$ \\
\hline Médias & 8,4 & 19,2 \\
\hline CV (\%) & 19,4 & 25,2 \\
\hline
\end{tabular}

Médias seguidas da mesma letra, na coluna, não diferiram entre si pelo teste de Tukey, a 5\% de significância;

${ }^{\text {ns }}=$ não significativo. encontrarem em ciclo reprodutivo (Figura 1), em que há competição por fotoassimilados e nutrientes entre os órgãos vegetativos e reprodutivos. Isso não ocorreu nas plantas semeadas em 15/09/07 em razão do ciclo mais prolongado. Em geral, o espaçamento de semeadura mais denso entre as plantas (espaçamento $2,5 \times 2,5 \mathrm{~m}$ ) apresentou valores superiores de cobertura de solo em relação ao menos denso (espaçamento $5 \times 5 m$ ). Como consequência, variando-se apenas o espaçamento de semeadura, o modo de desenvolvimento das plantas é modificado (RESENDE \& COSTA, 2003), favorecendo, assim, a rápida cobertura do solo. Também observou-se que o plantio mais tardio favorece rápida cobertura de solo, sendo explicado pelo maior crescimento vegetal da espécie em resposta aos fatores ambientais, principalmente temperatura do ar (Tabela 1 e 2).

Aos 150DAE, houve uma diminuição da cobertura do solo em relação às demais avaliações (Tabela 2), em razão da senescência das folhas das plantas. Entretanto, uma cobertura de solo superior a 90\% em cultivos de cucurbitáceas pode ser considerada excelente. RESENDE \& COSTA(2003) observaram uma cobertura inferior a isso para a melancia e até 64DAE não foi superior a 75\%. BISOGNIN et al. (2004) verificou que a taxa de aumento foliar do porongo, aos 21 dias após a emergência, foi a menor entre as cucurbitáceas estudadas. Nesse sentido, com base nas equações de regressão (Tabela 2) entre a cobertura do solo e as épocas avaliadas, é possível afirmar que, para a cobertura de solo ser superior a $90 \%$, as seguintes orientações devem ser observadas: 90DAE para as plantas semeadas com densidade de 400 covas ha- ${ }^{-1}$ (espaçamento 5x5m) em 15/09/07; 60DAE para aquelas semeadas com densidade de 1600 covas ha-1 (espaçamento 2,5x2,5m) na época 15/09/07, em ambas densidades para a época de $06 / 10 / 07$, e na densidade de 400 covas ha $^{-1}$ em 27/10/07; já aos 30DAE para as plantas semeadas em 27/10/07, sob densidade maior. A configuração de cultivo que permita atingir rápida e elevada cobertura de solo torna-se uma prática desejável para qualquer espécie, em especial quando cultivada em sistema de plantio convencional, como é o caso da região.

Observa-se na tabela 3 que o diâmetro da base dos frutos, o comprimento, a espessura de casco e a produção de sementes por fruto não diferiram como resposta às densidades. Apenas o diâmetro central da cuia foi maior em semeadura mais densa (espaçamento 2,5x2,5m). Já BISOGNIN et al. (1992) observaram que a espessura de casco do porongo diminui com o aumento da densidade da semeadura. No entanto, na época de semeadura mais tardia, em (27/10), todas as variáveis morfológicas estudadas apresentaram menores valores 
Tabela 2 - Cobertura vegetal do solo, em valores médios e estimados por equações de regressão em duas densidades, três épocas de semeadura e cinco datas após a emergência no cultivo de porongo no planalto médio do Rio Grande do Sul.

\begin{tabular}{|c|c|c|}
\hline \multirow{2}{*}{ Época de semeadura } & \multicolumn{2}{|c|}{ Cobertura vegetal do solo (\%)------ } \\
\hline & 1600 covas ha $^{-1}$ & 400 covas ha $^{-1}$ \\
\hline $15 / 09 / 07$ & 0 & 0 \\
\hline 06/10/07 & 0 & 0 \\
\hline $27 / 10 / 07$ & 0 & 0 \\
\hline Média & 0 & 0 \\
\hline $15 / 09 / 07$ & 28,0 Ac & $7,7 \mathrm{Bb}$ \\
\hline 06/10/07 & $66,5 \mathrm{Ab}$ & $13,7 \mathrm{Bb}$ \\
\hline $27 / 10 / 07$ & 93,7 Аа & 72,7 Ba \\
\hline Média & 62,0 & 31,4 \\
\hline $15 / 09 / 07$ & $\begin{array}{l}\text { 92,7 Aa } \\
\text { 9á }\end{array}$ & ( n n n \\
\hline 06/10/07 & 97,5 Аа & 96,0 Aa \\
\hline $27 / 10 / 07$ & 97,7 Аа & 95,7 Aa \\
\hline Média & 96,0 & 87,3 \\
\hline $15 / 09 / 07$ & $\begin{array}{l}\text { 98,0 Аа } \\
\text { Aa }\end{array}$ & 93,5 Аа \\
\hline 06/10/07 & 96,2 Аа & 95,5 Аа \\
\hline $27 / 10 / 07$ & 90,5 Аа & $91,2 \mathrm{Aa}$ \\
\hline Média & 94,90 & 93,41 \\
\hline $15 / 09 / 07$ & $\begin{array}{l}\text { 25,5 Aa } \\
\text { Aasó }\end{array}$ & $30,0 \mathrm{Aa}$ \\
\hline 06/10/07 & 27,5 Aa & 30,2 Aa \\
\hline $27 / 10 / 07$ & 29,0 Аа & 30,5 Аa \\
\hline Média & 27,30 & 30,25 \\
\hline $15 / 09 / 07$ & $\begin{array}{l}\mathrm{y}=-2,59+1,10 \mathrm{x}+0,01 \mathrm{x}^{2}-0,00011 \mathrm{x}^{3} \\
R^{2}=0,96\end{array}$ & $y=-2,18-0,19 x+0,03 x^{2}-0,00020 x^{3} R^{2}=0,97$ \\
\hline 06/10/07 & $\begin{array}{l}\mathrm{y}=-0,12+2,92 \mathrm{x}+0,02 \mathrm{x}^{2}+0,00003 \mathrm{x}^{3} \\
R^{2}=0.99\end{array}$ & $y=-4,15+0,65 x+0,02 x^{2}-0,00015 x^{3} R^{2}=0,90$ \\
\hline & $y=1,79+4,23 x-0,05 x^{2}+0,00016 x^{3}$ & $\mathrm{y}=0,27+3,26 \mathrm{x}-0,03 \mathrm{x}^{2}+0,00007 \mathrm{x}^{3} R^{2}=0,99$ \\
\hline 27/10/07 & $R^{2}=0,98$ & \\
\hline
\end{tabular}

Médias seguidas pelas mesmas letras maiúsculas na linha e pelas mesmas letras minúsculas na coluna não diferem entre si pelo teste de Tukey, em nível de 5\% de significância. ${ }^{(1)} \mathrm{y}=$ cobertura do solo; $\mathrm{x}=0$, 30, 60, 90 e 150DAE.

em relação às demais épocas de semeadura (Tabela 3), com exceção para a espessura de casco, e a produção de sementes por fruto que não diferiu da época intermediária (6/10). Apesar de a dimensão dos frutos e massa de sementes relacionarem-se entre si, pois o crescimento do fruto é regulado pela produção de fitohormônios pelas sementes (BLEASDALE, 1977), observou-se um baixo coeficiente de correlação entre a massa de sementes por fruto e o diâmetro da base dos frutos $\left(r^{2}=0,21\right)$. Por outro lado, foram encontrados $\mathrm{r}^{2}$ de 0,46, 0,42 e 0,66 quando a massa de sementes por fruto foi correlacionada com o diâmetro central, o comprimento e a espessura dos frutos, respectivamente. A produtividade de porongo tendeu a ser maior na época precoce de semeadura com a maior densidade de semeadura, porém apresentou menor tamanho de fruto, resposta comum nas Cucurbitaceae (RESENDE \& COSTA, 2003).

Em função do exposto, é desejável sob sistema de plantio convencional uma maior e mais rápida cobertura de solo, com a manutenção da produtividade. Os resultados aqui obtidos indicam que o plantio de porongo realizado na maior densidade e em épocas mais tardias, durante a estação de crescimento, constitui-se em uma alternativa viável à configuração de cultivo tradicional. 
Tabela 3 - Dados morfológicos e produtividade de frutos de porongo em função da densidade e das épocas de semeadura.

\begin{tabular}{|c|c|c|c|c|c|}
\hline & $\begin{array}{l}\text { Diâmetro da base do } \\
\text { fruto }(\mathrm{cm})\end{array}$ & $\begin{array}{l}\text { Diâmetro central do } \\
\text { fruto }(\mathrm{cm})\end{array}$ & $\begin{array}{l}\text { Comprimento dos } \\
\text { frutos }(\mathrm{cm})\end{array}$ & $\begin{array}{l}\text { Espessura do casco } \\
(\mathrm{mm})\end{array}$ & $\begin{array}{l}\text { Massa de semente } \\
\quad\left(\mathrm{kg} \mathrm{fruto}^{-1}\right)^{(1)}\end{array}$ \\
\hline \multicolumn{6}{|c|}{ 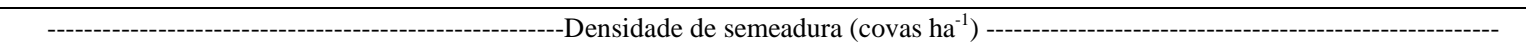 } \\
\hline 1600 & 61,75 & 30,16 a & 34,61 & 13,56 & 0,0985 \\
\hline \multicolumn{6}{|c|}{-------Época de semeadura------ } \\
\hline $15 / 09 / 07$ & 62,96 a & 30,05 a & $33,70 a b$ & 14,34 a & 0,1016 a \\
\hline 06/10/07 & 62,47 a & 29,76 a & 35,67 a & $13,43 \mathrm{ab}$ & $0,0988 a b$ \\
\hline $27 / 10 / 07$ & $58,50 \mathrm{~b}$ & $28,23 \mathrm{~b}$ & $32,96 \mathrm{~b}$ & $11,40 \mathrm{~b}$ & 0,0909 b \\
\hline Média & 61,31 & 29,35 & 34,11 & 13,06 & 0,0971 \\
\hline CV (\%) & 4,20 & 4,02 & 4,80 & 12,89 & 7,87 \\
\hline Época de semeadura & \multicolumn{3}{|c|}{ Densidade de semeadura (covas ha ${ }^{-1}$ ) } & \multicolumn{2}{|l|}{ Frutos ha ${ }^{-1}$} \\
\hline \multirow{2}{*}{$15 / 09 / 07$} & \multicolumn{3}{|c|}{1600} & \multicolumn{2}{|l|}{$17.866,66$} \\
\hline & \multicolumn{3}{|c|}{400} & \multicolumn{2}{|l|}{$10.746,66$} \\
\hline \multirow{2}{*}{ 06/10/07 } & \multicolumn{3}{|c|}{1600} & \multicolumn{2}{|l|}{$17.493,33$} \\
\hline & \multicolumn{3}{|c|}{400} & \multicolumn{2}{|l|}{$9.733,33$} \\
\hline \multirow{4}{*}{$27 / 10 / 07$} & \multicolumn{3}{|c|}{1600} & \multicolumn{2}{|c|}{$15.416,66^{(P=0,027)(2)}$} \\
\hline & \multicolumn{3}{|c|}{400} & \multicolumn{2}{|l|}{$10.416,66$} \\
\hline & \multicolumn{2}{|l|}{ Média } & & \multicolumn{2}{|l|}{$13.612,21$} \\
\hline & \multicolumn{2}{|l|}{$\mathrm{CV}(\%)$} & & \multicolumn{2}{|l|}{27,0} \\
\hline
\end{tabular}

Médias seguidas da mesma letra, na coluna, não diferiram entre si pelo teste de Tukey, a 5\% de significância; ns: não significativo. C.V. = coeficiente de variação. ${ }^{(1)}$ sementes a $20 \%$ de umidade. ${ }^{(2)}$ Significativo pelo teste T. ${ }^{\text {ns }}=$ não significativo.

\section{CONCLUSÃO}

As plantas semeadas na época mais tardia, na estação de crescimento, apresentam maior comprimento das ramas principais e, por consequência, mais rápida cobertura do solo; porém, esse procedimento resultou em plantas com ciclo menor, assim como menor dimensão de frutos, tendendo também à menor produtividade de frutos.

A densidade de semeadura de 1600 covas ha $^{-1}$ proporcionou mais rápida cobertura de solo e maiores produtividades de frutos (cuias) que o cultivo sob menor densidade, de 400 covas ha-1.

\section{AGRADECIMENTO}

O primeiro autor agradece ao Conselho Nacional de Desenvolvimento Científico e Tecnológico (CNPq), pela concessão de bolsa de iniciação científica CNPq/UPF no período de realização do trabalho.

\section{REFERÊNCIAS}

BISOGNIN, D.A. Origin and evolution of cultivated cucurbits. Ciência Rural, v.32, n.4, p.715-723, 2002. Disponível em: $<$ http://www.scielo.br/pdf/cr/v32n4/a28v32n4.pdf>. Acesso em: 16 abr. 2009. doi: 10.1590/S0103-84782002000400028.

BISOGNIN, D.A.; STORCK L. Estimativa dos componentes de variância e herdabilidade para formato de fruto em porongo - Lagenaria siceraria (Mol.) Standl. Ciência Rural, v.30, n.4, p.593-597, 2000. Disponível em: <http://www.scielo.br/scielo.php?pid=S010384782000000400006\&script=sci_arttext>. Acesso em: 16 abr. 2009. doi: 10.1590/S0103-84782000000400006.

BISOGNIN, D.A. et al. Densidade de semeadura e produtividade do porongo. Ciência Rural, v.22, n.1, p.15-19, 1992.

BISOGNIN, D.A. et al. Influência da época de extração na qualidade fisiológica de sementes de porongo. Ciência Rural, v.29, n.1, p.7-12, 1999. Disponível em: http://www.scielo.br/ $\mathrm{pdf} / \mathrm{cr} / \mathrm{v} 29 \mathrm{n} 1 / \mathrm{a} 02 \mathrm{v} 29 \mathrm{n} 1 . \mathrm{pdf}>$. Acesso em: 16 abr. 2009. doi: 10.1590/S0103-84781999000100002.

BISOGNIN, D.A. et al. Germinação e propagação in vitro de porongo. Ciência Rural, v.38, p.332-339, 2008. Disponível em: <http://www.scielo.br/pdf/cr/v38n2/a06v38n2.pdf>. Acesso em: 16 abr. 2009. doi: 10.1590/S0103-84782008000200006. 
BISOGNIN, D.A. et al. Efeito do tamanho de fruto e do método de extração na qualidade fisiológica de sementes de porongo. Ciência Rural, v.27, n.l, p.13-19, 1997. Disponível em: $<$ ht tp://www.scielo.br/scielo.php?pid=S 0103 $84781997000100003 \&$ script $=$ sci_arttext $>$. Acesso em: 16 abr. 2009. doi: 10.1590/S0103-84781997000100003.

BISOGNIN, D.A. et al. Contribuição das folhas cotiledonares para o crescimento e estabelecimento de plântulas de cucurbitáceas. Horticultura Brasileira, v.22, n.2, p.309313, 2004. Disponível em: <http://www.scielo.br/pdf/hb/v22n2/ 21037.pdf $>$. Acesso em: 16 abr. 2009. doi: 10.1590/S010205362004000200029

BLEASDALE, J.K.A. Fisiologia vegetal. Trad. WEISHAUPL, L.; LAMBERTI, A. São Paulo: EPU-EDUSP, 1977. 169p.

BORTOLUZZI, E.C.; ELTZ, F.L.F. Efeito do manejo mecânico da palhada de aveia preta sobre a cobertura, temperatura e teor de água no solo e emergência da soja em sistema plantio direto.
Revista Brasileira de Ciência do Solo, v.24, n.2, p.449457, 2000.

ELTZ, F.L.F. et al. Efeito do manejo do solo e de doenças foliares sobre a produção e qualidade da melancia. Revista Brasileira de Agrociência, v.11, n.2, p.201-206, 2005 Disponível em: <http://www.ufpel.tche.br/faem/agrociencia/ v11n2/artigo11.pdf>. Acesso em: 16 abr. 2009.

RESENDE, G.M.; COSTA, N.D. Características produtivas da melancia em diferentes espaçamentos de plantio. Horticultura Brasileira, v.21, n.4, p.695-698, 2003. Disponível em: <http:/ /www.scielo.br/pdf/hb/v21n4/19441.pdf>. Acesso em: 16 abr. 2009. doi: 10.1590/S0102-05362003000400025.

RESENDE, G.M. et al. Cultivo da melancia. Petrolina-PE: Embrapa Semi-Árido, Sistema de produção, 2006. (Boletim técnico, 4). ISSN 1807-0027. Versão eletrônica. Disponível em: <http:/ /www.cpatsa.embrapa.br/sistema_producao/spmelancia/clima.htm. 2006>. Acesso em: 16 abr. 2009. 